\title{
A formation of the heat pump mathematical models
}

\author{
A Y Marinchenko ${ }^{1}$ and A V Edelev ${ }^{1}$ \\ ${ }^{1}$ Melentiev Energy Systems Institute of Siberian Branch of SB RAS, Lermontov St. \\ 130, Irkutsk, Russia, 664033 \\ E-mail: marinchenko@isem.irk.ru, flower@isem.irk.ru
}

\begin{abstract}
The paper addresses the mathematical modeling heat pump main elements and heat pump based heat supply systems. It is used in the calculating expected heat supply costs on the basis of a heat supply system functioning simulation. Using these models, the current state of the heat pump NT-60-1 located in the Baikal Museum of the Scientific Center of the Siberian Branch of the Russian Academy of Sciences in Listvyanka was analyzed. Recommendations on improving the heat pump efficiency are given.
\end{abstract}

\section{Introduction}

The existing Russian district heat supply systems use the thermal power plants that produce combined heat and electricity as heat sources. The boiler houses of various types are heat sources in other heat supply systems.

One of the ways to increase the energy efficiency of district heating systems is to use a heat pump (HP) technology, which pick over heat from surface or underground water, industrial or domestic waste water, etc., and transfer it to the consumer with consuming a certain quantity of electricity. The fuel consumption to produce the same heat amount by the HP is lower than by the boiler house.

Installing heat pump units in the existing boiler houses burning coal and fuel oil and located within areas with increased environmental requirements (Lake Baikal zone, etc.) will greatly reduce the fuel consumption. It results in the significant improvement of the environmental situation in a region.

The most promising load for the HP is heating and hot water production. The heat is released in the form of hot water with the relatively low temperature (according to the temperature plan $95 / 70^{\circ} \mathrm{C}$ or lower). Under these conditions the HP provides significant fuel savings. However, the heat load depends on the outdoor temperature and varies significantly during day and according to the seasons of the year. Possible random deviations of various kinds lead to the necessity of using variable HP operation modes, redundancy and covering peak loads by other usually less capital-intensive heat sources.

Significant opportunities to improve the efficiency of a HP based heat supply system are also available due to the optimization of equipment size and its operation.

This work addresses the formation of mathematical models of the HP main elements and heat supply systems based on HP to use them in the calculating the expected heat supply system costs on the basis of the heat supply system functioning simulation.

The rest of the paper is structured as follows. Section 2 and 3 give a brief overview of the use of the HP in heat supply systems and related work, respectively. Section 4 presents a framework for mathematical modeling HP main elements. Section 5 describes testing proposed mathematical models. Section 6 concludes the paper.

Copyright (C) 2020 for this paper by its authors. Use permitted under Creative Commons License Attribution 4.0 International (CC BY 4.0). 


\section{The use of heat pumps in heat supply systems}

The HP is a device that uses the phase transitions of the working fluid (evaporation and condensation) to pick up energy from a low potential source (evaporation) and transfer it to a consumer with high temperature (condensation). The theoretical foundation of this process was presented in 1824 by S. Carnot. And in $1852 \mathrm{~W}$. Thompson (Lord Kelvin) created the first working HP.

A diagram of a heat supply system based on the HP is shown in Figure 1.

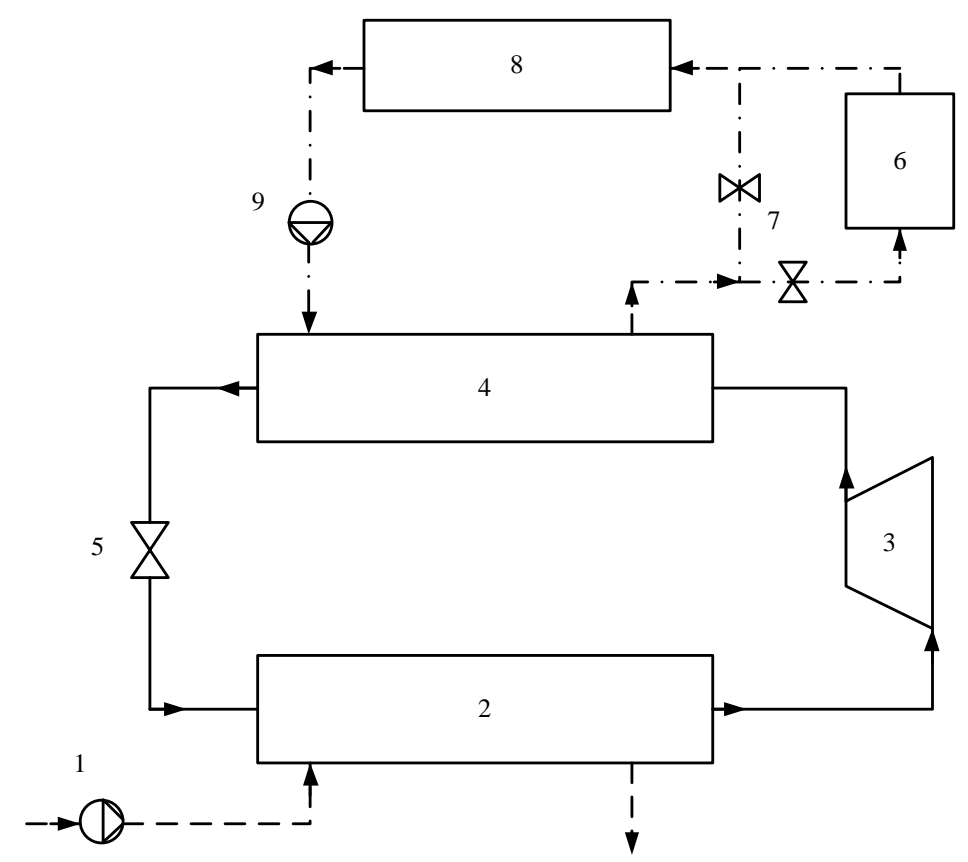

Figure 1. A diagram of a heat supply system based on the HP: 1 - pump; 2 - evaporator; 3 compressor with electric drive; 4 - condenser; 5 - thermostatic valve; 6 - electric boiler; 7 regulating water valves; 8 - heating devices; 9 - circulation pump of a heat supply system

The principles of operation of the heat supply system in Figure 1 are as follows:

1. In heat exchanger 2 or evaporator thermal energy from an external heat source is transferred to the HP working fluid known as a refrigerant.

2. The refrigerant evaporates and moves to the compressor 3 , which compresses it to a certain value. The refrigerant temperature, pressure, and enthalpy increase.

3. The compressed refrigerant moves through a heat exchanger 4 (condenser), in which the refrigerant condenses and transfers heat to water in a consumer's side system.

4. The refrigerant enters a throttle valve 5, which reduces the refrigerant pressure, and then it moves to the evaporator 2.

5. After the condenser 4 water in a consumer's side system flows to heating devices 8 . If it is necessary, the electric boiler 6 heats water up to the required temperature.

As noted above, it is possible to increase the efficiency of the HP based heat supply systems optimizing their design and operation. This optimization can be carried out on the basis of the methodology for calculating the expected heating costs based on the heat supply system functioning simulation.

\section{Related work}

Significant economic and environmental advantages make the HP a promising technology in the field of heat supply for most regions and countries of the world. A number of various heat pumps types units are operating in many countries now [1-4]. Their number is increasing every year. The total number of installed HP units in the world exceeds 100 million. Many countries provide substantial support to households that use heat pumps through national energy conservation programs. It should 
be noted that the majority (about 68\%) of new HP units have the capacity of up to $15 \mathrm{~kW}$ that corresponds to the heat requirements of a separate house with the heated living area of $140 \mathrm{~m}^{2}$. At the same time, there are quite big heat pumps units. Existing centralized district heat supply systems which use boiler houses as a heat source can be upgraded with combined installations, including the HP.

A significant amount of work has been devoted to the methods of mathematical modeling and optimization of various HP types and heat-producing plants based on them [1-7]. Usually mathematical modeling is used to study of thermodynamic cycles [3, 8-11], determine the best working fluids for the HP [14-17], increase the thermodynamic [5, 7-10, 16-19] and economic efficiency of HP units [6, 7, 11, 19-22].

The specificity of our study is that the developed HP models will be used to investigate the application of environmental technologies in the Baikal natural territory infrastructure.

\section{Mathematical models of the HP elements}

One of the main HP elements is a compressor, in which the process of compression of the working fluid occurs. In the design calculation of the compressor, the input flow rate, pressure and enthalpy of the working fluid, and its output pressure are known. The output enthalpy of the working fluid and maximum mechanical capacity of the compressor are calculated.

The mathematical representation of the compression process of the working fluid is described by the following dependencies:

$$
\begin{gathered}
S^{1}=f_{s p i}\left(P^{1}, H^{1}\right), \\
\left(H_{a d}\right)^{A}=f_{i p s}\left(P^{2}, S^{1}\right), \\
H^{2}=H^{1}-\left(H^{1}-\left(H_{a d}\right)^{A}\right) \cdot \eta_{o t s}, \\
N=G \cdot\left(H^{1}-H^{2}\right) \cdot \eta_{m},
\end{gathered}
$$

where $S$ is entropy; $N$ is capacity; $\eta_{o t s}$ is internal relative efficiency of the compressor; $\eta_{m}$ is mechanical efficiency of the compressor; $H_{a d}$ is enthalpy of the working fluid at the end of the ideal (adiabatic) process of compression to the outlet pressure, $P$ is the pressure; $G$ is the flow rate; $H$ is enthalpy of the working fluid. Hereinafter, superscript 1 marks input parameters, and 2 marks output parameters.

The HP condenser is to transfer heat from the working fluid to water in the consumer's side system. In this case, the working fluid converts from a vaporous state to a liquid state, i.e., it condenses. In the condenser a shell and tube construction is most often used. In this case, the heated water is passed inside the pipes, and the working fluid is condensed on the outside of pipes in the inter-tube space.

The system of equations describing the operation of the HP condenser includes the following dependencies:

- heat balance equation

$$
G_{w} \cdot\left(H_{w}^{2}-H_{w}^{1}\right)=\eta_{u t} \cdot\left[G_{p}^{1} \cdot\left(H_{p}^{1}-H_{p}^{2}\right)\right],
$$

- equation of material balance

$$
G_{\mathrm{p}}^{2}=G_{p}^{1}
$$

- heat transfer equation

$$
F=\frac{G_{w} \cdot\left(H_{w}^{2}-H_{w}^{1}\right)}{\Delta T_{\log } \cdot K} \cdot \eta_{s},
$$


where $G$ is flow rate, $H$ is enthalpy, $\eta_{u t}$ is heat exchanger heat utilization coefficient, $F$ is heating surface area, $\Delta T_{\log }$ is logarithmic temperature head, $\eta_{s}$ is heat exchanger safety factor on the heating surface, $K$ is heat transfer coefficient. Hereinafter, subscripts "p" and "w" denote the parameters related to the HP working fluid and water, respectively.

Dependencies for determining the logarithmic temperature head are

$$
\begin{gathered}
T_{s a t}=f_{t p H}\left(P_{p}\right), \\
T_{w}^{1}=T_{s a t}-\Delta T_{k}, \\
T_{w}^{2}=f_{t p i}\left(P_{w}^{2}, H_{w}^{2}\right), \\
\Delta T_{\log }=\frac{\left(T_{s a t}-T_{w}^{1}\right)-\left(T_{s a t}-T_{w}^{2}\right)}{\ln \left(\frac{T_{s a t}-T_{w}^{1}}{T_{s a t}-T_{w}^{2}}\right)},
\end{gathered}
$$

where $T_{s a t}$ is saturation temperature at an average pressure of the working fluid in the heat exchanger; $\Delta T_{k}$ is end temperature pressure (at the outlet of water from the heater).

The relationship between the enthalpy of water and temperature is

$$
H_{w}^{2}=f_{i p t}\left(P_{w}^{2}, T_{w}^{2}\right) .
$$

Dependence for determining the heat transfer coefficient is

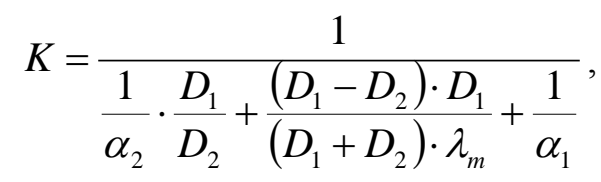

where $D_{1}$ and $D_{2}$ are the outer and inner diameters of the pipes, respectively, $\alpha_{1}$ is the heat transfer coefficient from the working fluid to the pipe, $\alpha_{2}$ is the heat transfer coefficient from the pipe to water, $\lambda_{m}$ is the thermal conductivity of the pipe metal. The heat transfer coefficient $\alpha_{1}$ is determined by the procedure described in [23] for the liquid condensation.

Dependencies for determining the hydraulic resistance of a condenser along the path of the working fluid and water are

$$
\begin{gathered}
P_{w}^{2}=P_{w}^{1}-\frac{\left(\xi_{t p}^{t}+\xi_{m}^{t}\right) \cdot\left(W_{w}^{c p}\right)^{2}}{2 \cdot g \cdot V_{w}^{c p}}, \\
P_{p}^{2}=P_{p}^{1}-0,33 \cdot \frac{\left(\xi_{t p}^{n}+\xi_{m}^{n}\right) \cdot\left(W_{p}^{1}\right)^{2}}{2 \cdot g \cdot V_{p}^{1}},
\end{gathered}
$$

where $g$ is the acceleration of gravity, $W$ is the speed of water or steam, and $V$ is the specific volume.

The coefficients of hydraulic friction and local losses $\xi_{t p}^{n}, \xi_{m}^{n}, \xi_{t p}^{t}, \xi_{m}^{t}$ for water inside the pipes and for washing the pipe bundle are calculated in accordance with the standard calculation method:

$$
Z_{t p}=\frac{G_{w}^{1} \cdot V_{w}^{c h}}{4 \cdot \pi \cdot W_{w}^{c h} \cdot\left(D_{2}\right)^{2}},
$$




$$
\begin{gathered}
L_{t p}=\frac{F}{\pi \cdot Z_{t n} \cdot D_{1}}, \\
Z_{\text {row }}=\frac{F \cdot W_{p}^{1} \cdot\left(S_{1}-D_{1}\right)}{\pi \cdot D_{1} \cdot G_{p}^{1} \cdot V_{h}^{1}} .
\end{gathered}
$$

where $Z_{t p}$ is number of pipes connected in parallel; $L_{t p}$ is average length of one pipe; $Z_{\text {row }}$ is number of rows of pipes along the steam flow; $S_{1}$ is transverse (along the working body) pipe pitch.

The initial data for the modeling condenser are the flow rate, enthalpy and pressure of the heated water at the inlet, the pressure and enthalpy of the working fluid, the speeds of the working fluid and water, the inner and outer diameters of the pipes, and their transverse steps. The flow rate of the working fluid, the enthalpy and pressure of the water at the outlet, the enthalpy and pressure of the working fluid at the outlet, the surface area of the heating, the number of pipes, the number of rows of pipes along the working fluid, etc., are determined.

The HP evaporator is to take heat from a low-temperature heat source at low temperature and transfer it to the working fluid; while the working fluid converts from the liquid phase to the gaseous one.

The system of equations describing the heat transfer process in the evaporator is:

- heat balance equation

$$
G_{w} \cdot\left(H_{w}^{1}-H_{w}^{2}\right)=\eta_{u t} \cdot\left[G_{p}^{1} \cdot\left(H_{p}^{2}-H_{p}^{1}\right)\right],
$$

- material balance equation

$$
G_{\mathrm{p}}^{2}=G_{p}^{1},
$$

- heat transfer equation

$$
F=\frac{G_{w} \cdot\left(H_{w}^{1}-H_{w}^{2}\right)}{\Delta T_{\log } \cdot K} \cdot \eta_{3} .
$$

Dependencies for determining the logarithmic temperature pressure are

$$
\begin{gathered}
T_{s a t}=f_{t p H}\left(P_{p}\right), \\
T_{w}^{1}=T_{s a t}+\Delta T_{k}, \\
T_{w}^{2}=f_{t p i}\left(P_{w}^{2}, H_{w}^{2}\right), \\
\Delta T_{\log }=\frac{\left(T_{w}^{1}-T_{s a t}\right)-\left(T_{\mathrm{w}}^{2}-T_{s a t}\right)}{\ln \left(\frac{T_{w}^{1}-T_{s a t}}{T_{w}^{2}-T_{s a t}}\right)} .
\end{gathered}
$$

Dependencies for determining the heat transfer coefficient, the hydraulic resistance of the evaporator along the path of the working fluid and water, its design and layout characteristics are similar to the dependences (14)-(18) used in the modeling the condenser. The heat transfer coefficient $\alpha_{1}$ is determined by the method described in [23] for the bubble boiling process.

The initial data for the modeling evaporator are the enthalpy and pressure of the heated water at the inlet, the flow rate, the pressure and enthalpy of the working fluid, the speeds of the working fluid and water, the inner and outer diameters of the pipes, and their transverse steps. The water flow rate, enthalpy and pressure of the water at the outlet, the enthalpy of the working fluid at the outlet, the surface area of the heating, the number of pipes, the number of rows of pipes along the working fluid, etc. are determined. 
To calculate the thermodynamic and transport properties of the HP working fluid there is an approach that interpolates dependencies between given base (tabular) points at which the properties are known. The data for Freon R134a (http://www.coolprop.org/fluid_properties/fluids/index.html) were used as basic table values.

\section{Testing mathematical models}

The developed mathematical model was used to analyse the current state of the HP NT-60-1 located in the Baikal Museum of the Scientific Center of the Siberian Branch of the Russian Academy of Sciences in Listvyanka and to develop recommendations for improving its efficiency. The source of low-grade heat is the running water of the pools with a discharge temperature depending on the season $4-9{ }^{\circ} \mathrm{C}$ and a flow rate of about $20 \mathrm{~m}^{3} / \mathrm{h}$.

A general view of the HP NT-60-1 is shown in Figure 2. The scheme of the heat supply system of the Baikal Museum based on the NT-60-1 vapor compression HP is presented in Figure 3.

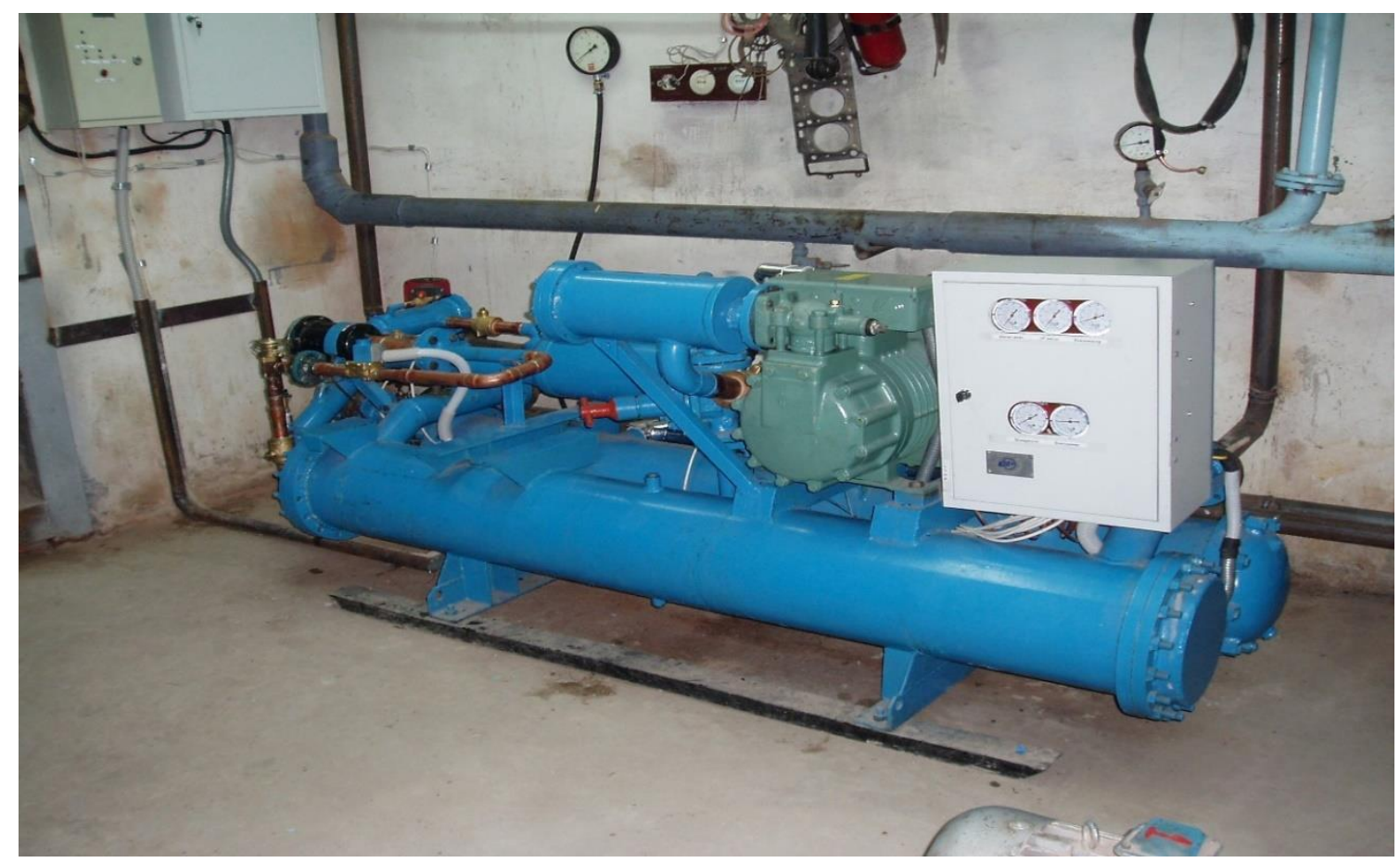

Figure 2. The HP NT-60-1 for the heat supply of the Baikal Museum of the Scientific Center of the Siberian Branch of the Russian Academy of Sciences on the basis of renewable heat of Lake Baikal water

The ozone-safe freon R-134a was used as the NT-60-1 working fluid, the HP scheme was developed taking into account the specifics of working with low-temperature renewable sources and provides higher conversion factors compared to traditional layout schemes. For this purpose an evaporator with an in-line boiling of the refrigerant was used, it is adapted for working conditions in cold Baikal water at low temperatures of the order of $2-4^{\circ} \mathrm{C}$, and schemes for joint operation of the HP with other heat sources, including electric boilers, were developed.

In addition, while working on cold heat sources in order to increase the specific HP heat output, it is planned to heat the low-grade heat carrier (Baikal water) in front of the evaporator due to the deep cooling of the refrigerant condensate in the subcooler. In this case, all or part of water passes through the supercooler 8 . In the absence of the need for hot water supply, this operation scheme provides an increase in the overall efficiency of the vapor compression HP by minimizing irreversible losses in the throttle device. 
The estimated average annual HP coefficient of performance, which determines the ratio of heat generated to energy consumption of the compressor drive, was about 3.5. During the heating period the HP provides heating of water up to $60^{\circ} \mathrm{C}$ on the working fluid $\mathrm{R}-134 \mathrm{a}$, which corresponds to the HP design specifications. The HP was also worked together with the electric boiler, previously used in the museum's heating center for heating. The implementation of the scheme of their joint application for heat supply where the HP works on the base load and of electric works only on peak load, reduces the total heating energy consumption by $2-3$ times.

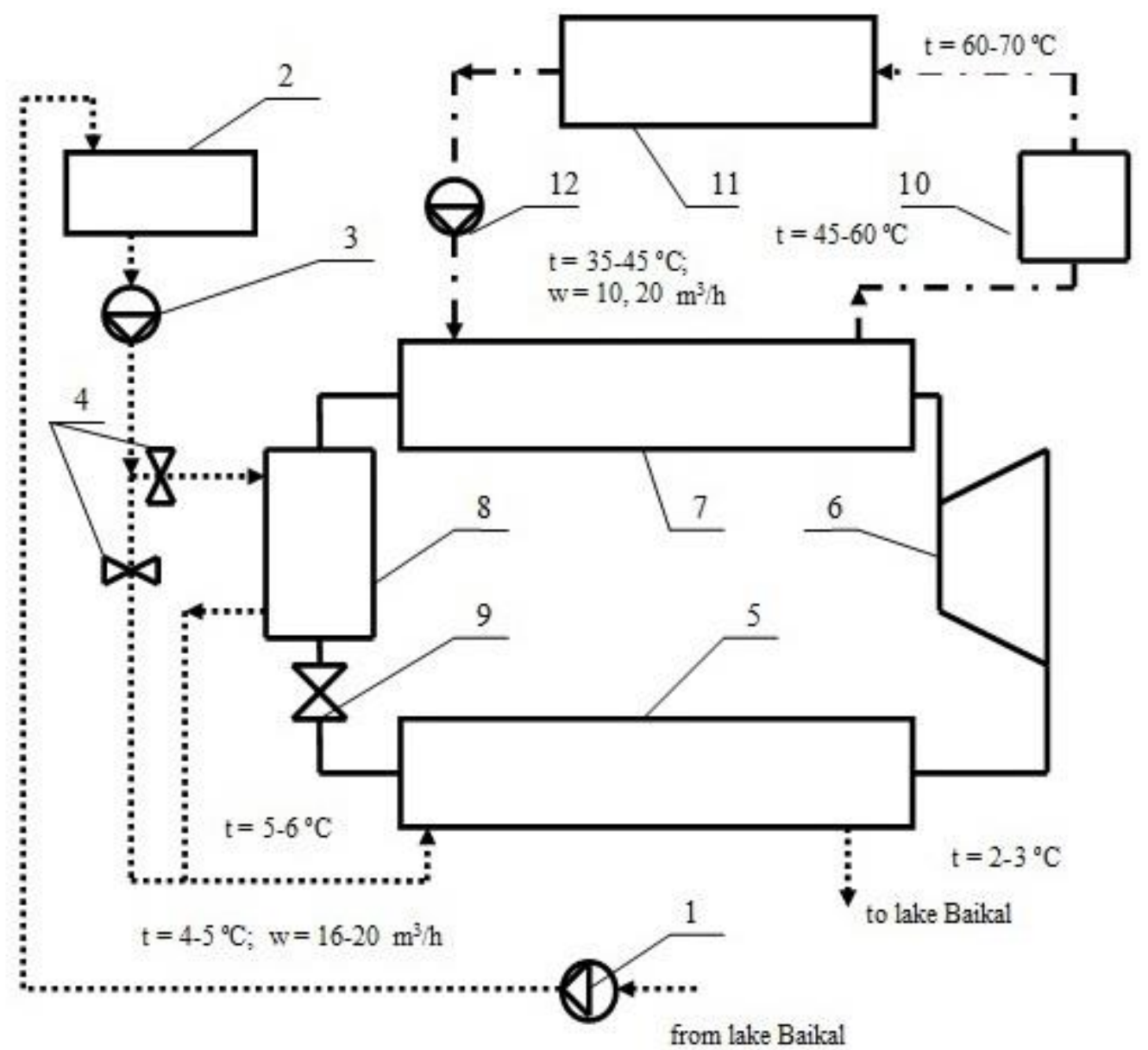

Figure 3. The schematic diagram of the Baikal Museum's heat supply system:

1 - pumping station; 2 - Museum's aquariums; 3 - pumping installation; 4 -regulating water valves; 5 - evaporator with internal coolant boiling; 6 - reciprocating compressor with electric drive; 7 -condenser; 8 - supercooler; 9 - temperature-regulating valve; 10 - electric boiler; 11 - heating devices; 12 - circulation pump of the heating system

Table 1 presents the nominal parameters of the HP NT-60-1 obtained from the operation manual. Table 2 presents the calculated HP parameters obtained using the mathematical model of the HP at the initial nominal parameters. As one can see from Table 2, the power consumption of the compressor of the HP is $24.9 \mathrm{~kW}$ at nominal temperatures at the outlet of the condenser and evaporator.

Table 1. The passport parameters of the HP NT-60-1

\begin{tabular}{lcc}
\hline & Dimension & Value \\
\hline Maximum power consumption & $\mathrm{kW}$ & 30.1 \\
Nominal flow rate per condenser & $\mathrm{m}^{3} / \mathrm{h}$ & 5 \\
Nominal evaporator water consumption & $\mathrm{m}^{3} / \mathrm{h}$ & 27.8 \\
Nominal water temperature at the condenser outlet & ${ }^{0} \mathrm{C}$ & $62 \pm 1$
\end{tabular}


Table 2. The HP NT-60-1 parameters calculated at nominal values

\begin{tabular}{lcc}
\hline & Dimension & Value \\
\hline Power consumption & $\mathrm{kW}$ & 24.9 \\
Condenser water flow & $\mathrm{m}^{3} / \mathrm{h}$ & 5 \\
Evaporator water consumption & $\mathrm{m}^{3} / \mathrm{h}$ & 27.8 \\
Condenser inlet water temperature & ${ }^{0} \mathrm{C}$ & 30 \\
Condenser outlet water temperature & ${ }^{0} \mathrm{C}$ & 60.9 \\
Evaporator inlet water temperature & ${ }^{0} \mathrm{C}$ & 7 \\
Evaporator outlet water temperature & ${ }^{0} \mathrm{C}$ & 2.48 \\
Coefficient of performance & & 3.4 \\
\hline
\end{tabular}

Table 3 shows the existing state of the NT-60-1. It should be noted that the water flow in the heat supply system was unknown, so in this case it was calculated according to the heat balance equation, taking into account losses in the HP. Also a fairly low value of the coefficient of performance of the HP indicates that its efficiency is rather low.

Table 3. The real HP NT-60-1 parameters

\begin{tabular}{lcc}
\hline & Dimension & Value \\
\hline Power consumption & $\mathrm{kW}$ & 26 \\
Condenser water flow & $\mathrm{m}^{3} / \mathrm{h}$ & 7 \\
Evaporator water consumption & $\mathrm{m}^{3} / \mathrm{h}$ & 16 \\
Condenser inlet water temperature & ${ }^{0} \mathrm{C}$ & 49 \\
Condenser outlet water temperature & ${ }^{0} \mathrm{C}$ & 59 \\
Evaporator inlet water temperature & ${ }^{0} \mathrm{C}$ & 6.4 \\
Evaporator outlet water temperature & ${ }^{0} \mathrm{C}$ & 3.2 \\
Coefficient of performance & & 1.54 \\
\hline
\end{tabular}

Table 4 presents the NT-60-1 parameters calculated under the same conditions as in Table 3, except for the return water temperature, which was adopted at $42^{\circ} \mathrm{C}\left(7^{\circ} \mathrm{C}\right.$ lower than before). As one can see from Table 4, it is allowed for almost the same electricity consumption value to double the efficiency of the NT-60-1 (coefficient of performance is 2.7)

Table 4. The recommended HP NT-60-1 parameters

\begin{tabular}{lcc}
\hline & Dimension & Value \\
\hline Power consumption & $\mathrm{kW}$ & 25.6 \\
Condenser water flow & $\mathrm{m}^{3} / \mathrm{h}$ & 7 \\
Evaporator water consumption & $\mathrm{m}^{3} / \mathrm{h}$ & 16 \\
Condenser inlet water temperature & ${ }^{0} \mathrm{C}$ & 42 \\
Condenser outlet water temperature & ${ }^{0} \mathrm{C}$ & 59.9 \\
Evaporator inlet water temperature & ${ }^{0} \mathrm{C}$ & 6.4 \\
Evaporator outlet water temperature & ${ }^{0} \mathrm{C}$ & 1.8 \\
Coefficient of performance & & 2.7 \\
\hline
\end{tabular}

The main recommendation drown from the results of the experimental analysis is to increase the flow rate of low-grade water through the evaporator to nominal values. This will bring the parameters of NT-60-1 to ones given in the passport and significantly increase the efficiency of the HP. A decrease in the temperature at the inlet of the condenser to $30-35^{\circ} \mathrm{C}$ and at the output of the condenser 
to $50^{\circ} \mathrm{C}$ will also have a positive effect, which will lead to a decrease in the compressor energy consumption without reducing the thermal efficiency of the HP.

\section{Conclusions}

In the paper, we focused on the problem of the HP use study. It is a relevant problem. This is due to significant economic and environmental advantages the HP use.

To this end, we have proposed the specialized mathematical models for modeling and studying the operation efficiency of HP under its practical use. Based on the experimental analysis, we have formed useful recommendations related to improving the functioning of this HP.

Our future work related to applying the proposed models in calculating the expected heat supply system costs.

\section{Acknowledgments}

The study is supported by the Russian Foundation of Basic Research and Government of Irkutsk Region, project no. 20-47-380002. We sincerely thank the director, scientific leader, management, and employees of the Baikal Museum for advising and expert supporting in our study.

\section{References}

[1] Bonin J. 2015 Heat pump planning handbook (Routledge, New York)

[2] Fischer D and Madani H 2017 On heat pumps in smart grids: A review Renewable and Sustainable Energy Reviews 70 342-357

[3] Arpagaus C, Bless F, Schiffmann J. and Bertsch S S 2016 Multi-temperature heat pumps: A literature review Int J Refrig 69 437-465.

[4] Rees S ed. 2016 Advances in ground-source heat pump systems (Woodhead Publishing)

[5] Wallerand A S, Kermani M, Kantor I and Maréchal F 2018 Optimal heat pump integration in industrial processes Applied Energy 219 68-92

[6] Averfalk H, Ingvarsson P, Persson U, Gong M and Werner S 2017 Large heat pumps in Swedish district heating systems Renewable and Sustainable Energy Reviews 79 1275-1284

[7] Simonetti R, Moretti L, Molinaroli L and Manzolini G 2020 Energetic and economic optimization of the yearly performance of three different solar assisted heat pump systems using a mixed integer linear programming algorithm Energy Convers. Manag. 206112446

[8] Mota-Babiloni A, Mateu-Royo C, Navarro-Esbrí J, Molés F, Amat-Albuixech M and BarragánCervera Á 2018 Optimisation of high-temperature heat pump cascades with internal heat exchangers using refrigerants with low global warming potential Energy 165 1248-1258

[9] Culha O, Gunerhan H, Biyik E, Ekren O and Hepbasli A 2015 Heat exchanger applications in wastewater source heat pumps for buildings: A key review Energy Build. 104 215-232

[10] Zhang Q, Yang S, Shi P, Hou W, Zeng A, Ma Y and Yuan X 2020 Economically and thermodynamically efficient heat pump-assisted side-stream pressure-swing distillation arrangement for separating a maximum-boiling azeotrope Appl. Therm. Eng. 173115228

[11] Blázquez C S, Verda V, Nieto I M, Martín A F and González-Aguilera D 2020 Analysis and optimization of the design parameters of a district groundwater heat pump system in Turin, Italy Renew. Energ. 149 374-383

[12] Bamigbetan O, Eikevik T M, Neksa P and Bantle M 2017 Review of vapour compression heat pumps for high temperature heating using natural working fluids Int. J. Refrig. 80 197-211

[13] Zühlsdorf B, Jensen J K and Elmegaard B 2019 Heat pump working fluid selection-economic and thermodynamic comparison of criteria and boundary conditions Int. J. Refrig. 98 $500-513$

[14] Uusitalo A, Turunen-Saaresti T, Honkatukia J, Tiainen J and Jaatinen-Värri A 2020 Numerical analysis of working fluids for large scale centrifugal compressor driven cascade heat pumps upgrading waste heat Applied Energy 269115056

[15] Brodal E and Eiksund O 2020 Optimization study of heat pumps using refrigerant blendsEjector versus expansion valve systems Int. J. Refrig. 111 136-146

[16] Willem H, Lin Y and Lekov A 2017 Review of energy efficiency and system performance of 
residential heat pump water heaters Energy Build. 143 191-201

[17] Kim B, Lee S H, Lee D and Kim Y 2020 Performance comparison of heat pumps using low global warming potential refrigerants with optimized heat exchanger designs Appl. Therm. Eng. 171114990

[18] Peng X, Wang D, Wang G, Yang Y and Xiang S 2020 Numerical investigation on the heating performance of a transcritical $\mathrm{CO}_{2}$ vapor-injection heat pump system Appl. Therm. Eng. 166 114656

[19] Pinamonti M and Baggio P 2020 Energy and economic optimization of solar-assisted heat pump systems with storage technologies for heating and cooling in residential buildings Renew. Energ. 157 90-99

[20] Wang M, Deng C Wang Y and Feng X 2020 Exergoeconomic performance comparison, selection and integration of industrial heat pumps for low grade waste heat recovery Energy Convers. Manag. 207112532

[21] Deng J, He S, Wei Q, Li J, Liu H, Zhang Z and Zhang H 2020 Field test and optimization of heat pumps and water distribution systems in medium-depth geothermal heat pump systems Energy Build. 209109724

[22] Hou G, Taherian H, Li L, Fuse J and Moradi L 2020 System performance analysis of a hybrid ground source heat pump with optimal control strategies based on numerical simulations Geothermics 86101849

[23] Isachenko V P, Osipova V, Semyonov S, Sukomel 2000 A Heat transfer (University Press of the Pacific) 